\title{
Bran-New Four-Molecule and Five-Molecule Cascade Reactions for One-Pot Synthesis of Pyrano[3,2-c]chromen-5-ones and Spiro[benzo[b][1,4]diazepine-2,2'-pyrano[3,2-c]chromen]-5'-ones under Catalyst- and Solvent-Free Conditions
}

Guoxun Zhu, ${ }^{\dagger}$ Zhou Yi, ${ }^{\dagger}$ Jie Zhou, ${ }^{\dagger}$ Zhiyong Chen, ${ }^{\ddagger}$ Pengran Guo, ${ }^{\ddagger}$ Yanying Huang, ${ }^{\ddagger}$ Jianghan Chen, Huacan Song, ${ }^{* \dagger}$ and Wei Yi* ${ }^{\dagger} \dagger, \S(0)$

${ }^{\dagger}$ School of Chemical Engineering and Technology, Sun Yat-sen University, 135 Xin Gang West Road, Guangzhou 510275, P. R. China

${ }^{\ddagger}$ China National Analysis Center, Guangzhou 510070, P. R. China

${ }^{\S}$ Key Laboratory of Molecular Clinical Pharmacology \& Fifth Affiliated Hospital, Guangzhou Medical University, Guangzhou 511436, P. R. China

\section{Supporting Information}

\begin{abstract}
Herein, two versatile bran-new methods have been developed for building three new kinds of complicated-framework compounds including 2,4,4-trimethyl-2-(phenylamino)-3,4-dihydro$2 H, 5 H$-pyrano[3,2-c] chromen-5-ones, $4,4,4^{\prime}, 4^{\prime}$-tetramethyl-1,3,3',4,4',5hexahydro-5' $H$-spiro-[benzo $[b][1,4]$ diazepine-2,2' -pyrano[3,2-c]-chro-

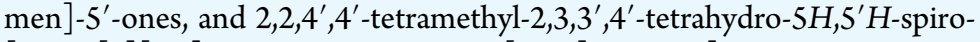
$\left[\right.$ benzo $[b][1,4]$-oxazepine- $4,2^{\prime}$-pyrano $[3,2-c]$ chromen $]-5^{\prime}$-ones in a onepot manner via four-molecule and five-molecule cascade reactions of commercially available 4-hydroxychromen-2-one, substituted anilines, and acetone. In consideration of these impressive features including no need of additional catalysts and solvents, moderate to good yields, excellent site-selectivity, and broad substrate/functional group tolerance, we believe that the two present protocols should have the potential for broad synthetic utility.
\end{abstract}

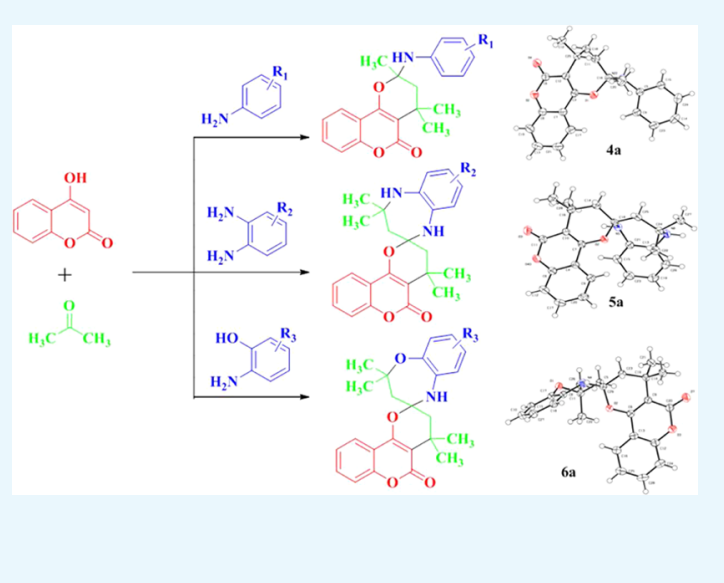

\section{INTRODUCTION}

Multi-component reaction (MCR) has emerged as one of the most popular and powerful approaches for the one-pot synthesis of important natural products, organic building blocks, and pharmaceutical intermediates. ${ }^{1,2}$ Because of the reduced number of reaction steps and simple operation, MCR usually leads to reduced waste of the starting materials and acceptable yields of the corresponding products in a step/atomeconomical and environmentally benign fashion. ${ }^{3,4}$ As a result, over the past decade, remarkable advances have been made on this topic. ${ }^{5-9}$ Despite this compelling progress, most studies often suffer from one or more of the following disadvantages, such as the compulsive dependence on heavy metal or expensive metal catalysts, ${ }^{10}$ and the utilization of harmful ${ }^{11}$ and/or expensive reagents. ${ }^{12}$ Undoubtedly, the further development of mild, efficient, and general MCRs for the direct assembly of a key structural motif is still highly desired. ${ }^{13}$

It is well-known that 4-hydroxychromen-2-one is a star molecule. To date, a large number of studies have demonstrated that it has a wide range of biological activities $^{15-17}$ including antioxidant activity, ${ }^{14}$ antibacterial activity, ${ }^{15}$ and anti-cancer activity. ${ }^{16}$ Moreover, a lot of classical organic synthetic reactions have showed that acetone can smoothly react with aniline to generate the electron-rich isopropenylphenylamine or iso-propylidenephenylamine. Alternatively, it could also easily react with 4-hydroxychromen-2-one to yield 3-iso-propylidenechroman-2,4-dione in decent yield. On the basis of these results and by analyzing the chemical properties of the two resulting compounds, we envisaged that the in situ combination of the above two condensed products might lead to the synthesis of interesting complex molecules via the Michael addition reaction under proper conditions. Inspired by this and in continuation of our interest in developing efficient protocols for the construction of valuable heterocyclic compounds, ${ }^{18}$ we herein explore the tandem reactions of 4hydroxychromen-2-ones, substituted anilines, and ketone compounds.

To this end, we succeeded in establishing two bran-new fourmolecule and five-molecule reactions of substituted anilines, 4hydroxychromen-2-one, and acetone under catalyst- and

Received: December 19, 2017

Accepted: March 1, 2018

Published: October 18, 2018 
Scheme 1. Bran-New Four-Molecule and Five-Molecule Reactions of Substituted Aniline, 4-Hydroxychromen-2-one, and Acetone

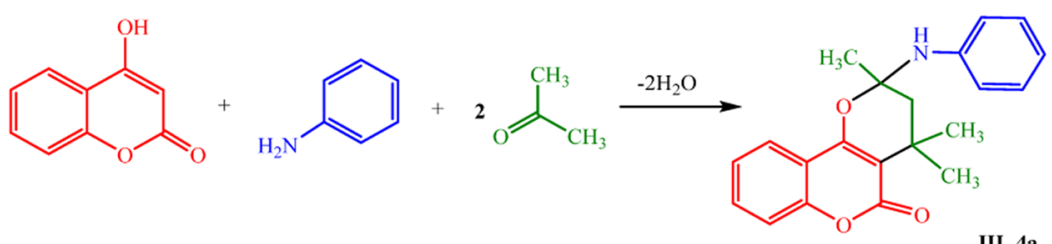

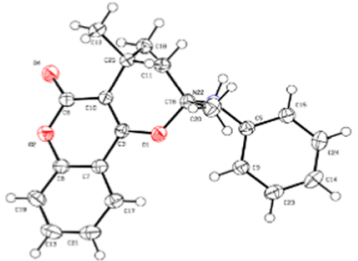

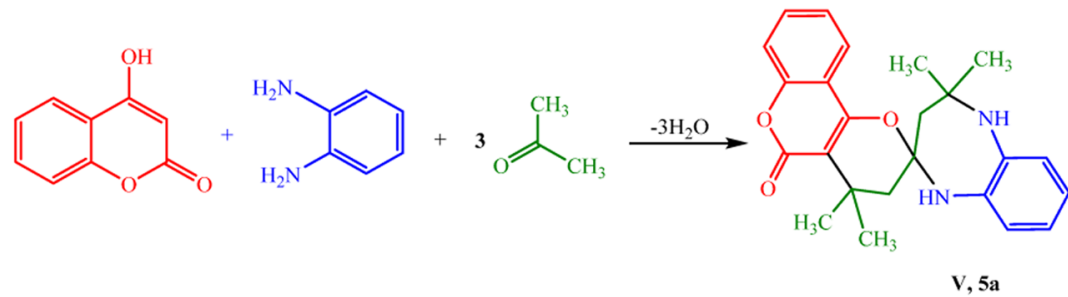

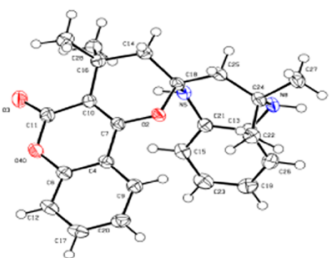

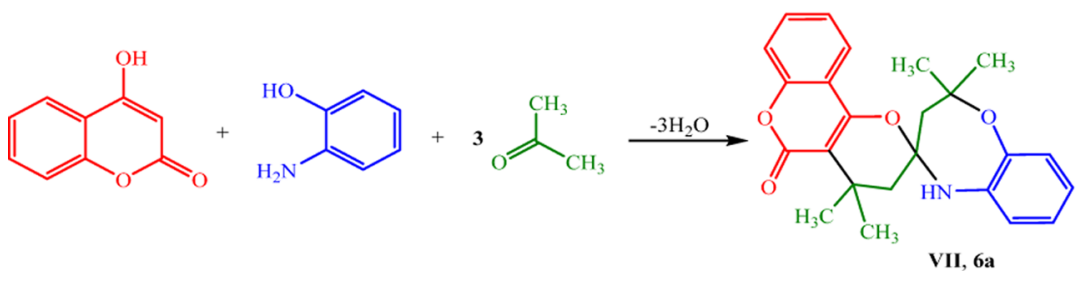

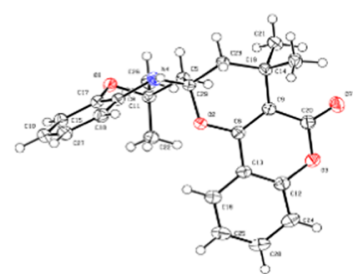

Scheme 2. Mechanism of the Four-Molecule Cascade Reaction of 4-Hydroxychromen-2-one, Aniline, and Acetone

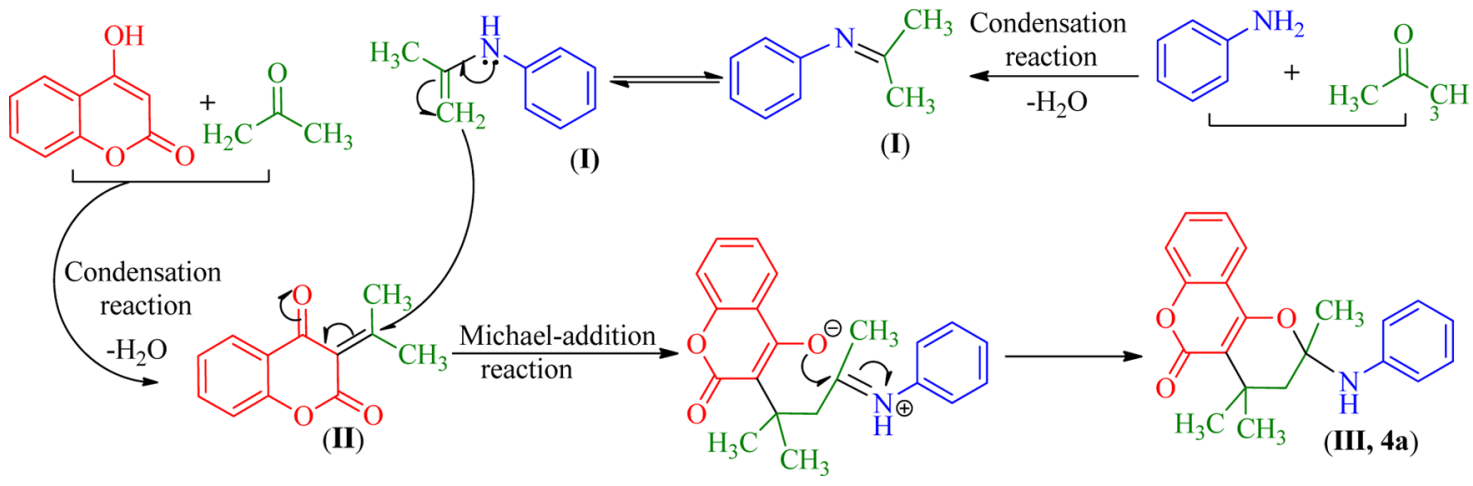

solvent-free reactions (Scheme 1). The structures of the products were identified by $\mathrm{X}$-ray single crystal diffraction, highresolution mass spectroscopy (HRMS), ${ }^{1} \mathrm{H}$ NMR, ${ }^{13} \mathrm{C}$ NMR, and elemental analysis. In addition, the possible reaction mechanism was rationally proposed on the basis of the experimental investigations.

Briefly, the first reaction was the intermolecular condensation of anilines, 4-hydroxy-chromen-2-ones, and acetone, which formed 2,4,4-trimethyl-2-(phenylamino)-3,4-dihydro- $2 \mathrm{H}, 5 \mathrm{H}$ pyrano[3,2-c]chromen-5-ones; the second reaction was the intermolecular condensation of 4-hydroxychromen-2-ones, acetone, and benzene-1,2-diamine or 2-amino-phenols, respectively, which generated $4,4,4^{\prime}, 4^{\prime}$-tetramethyl-1,3,3',4,4',5-hexahydro-5' $H$-spiro[benzo[b][1,4] diazepine-2,2' -pyrano[3,2-c]-

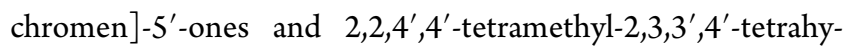
dro-5H,5' $H$-spiro[benzo $[b][1,4]$ oxazepine-4, $2^{\prime}$-pyrano[3,2-c]chromen]-5'-ones.

\section{RESULTS AND DISCUSSION}

Determination of the Structures of the Products by Xray Diffraction Analysis. 4-Hydroxychromen-2-one, acetone, and aniline, benzene-1,2-diamine, or 2-aminophenol, were respectively selected as the starting materials to obtain three desired products, 2,4,4-trimethyl-2-(phenylamino)-3,4-dihydro$2 \mathrm{H}, 5 \mathrm{H}$-pyrano-[3,2-c] chromen-5-one (4a), 4,4,4',4' -tetramethyl-1,3,3',4,4',5-hexahydro-5' $H$-spiro[benzo[b][1,4] diazepine$2,2^{\prime}$-pyrano[3,2-c]chromen]-5'-one (5a), and 2,2,4',4'-tetramethyl-2,3,3', $4^{\prime}$-tetrahydro- $5 H, 5^{\prime} H$-spiro[benzo $[b][1,4]$ oxazepine-4,2'-pyrano-[3,2-c]chromen $]-5^{\prime}$-one (6a). Their structures were further confirmed by single crystal X-ray analysis.

Mechanistic Speculation of the Reaction. First Kind of Reaction: Four-Molecule Reaction. To explore the reaction mechanism, a mixture of acetone, aniline, and 4-hydroxychromen-2-one was refluxed for $6 \mathrm{~h}$, and HRMS was run to probe the possible intermediates.

Gratefully, two key intermediates, iso-propylidenephenylamine (I) and 3-iso-propylidenechroman-2,4-dione (II), were 
Scheme 3. Mechanism of the Five-Molecule Cascade Reaction of 4-Hydroxychromen-2-one, Benzene-1,2-diamine, and Acetone

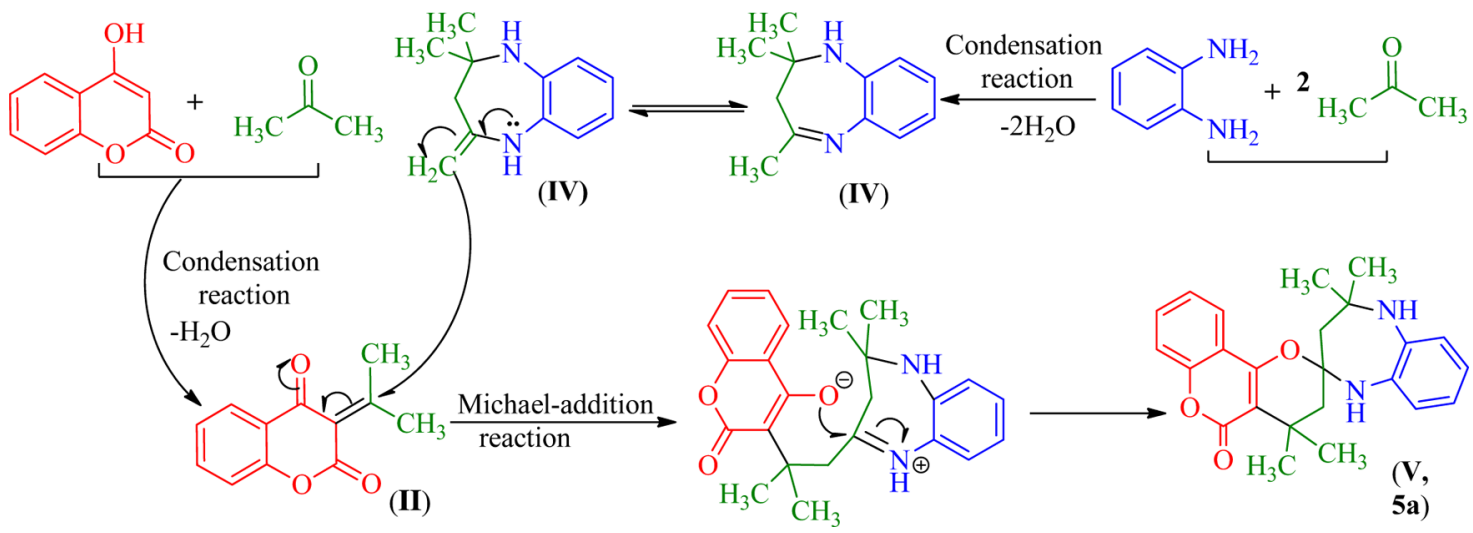

Scheme 4. Mechanism of the Five-Molecule Cascade Reaction of 4-Hydroxychromen-2-one, 2-Aminophenol, and Acetone

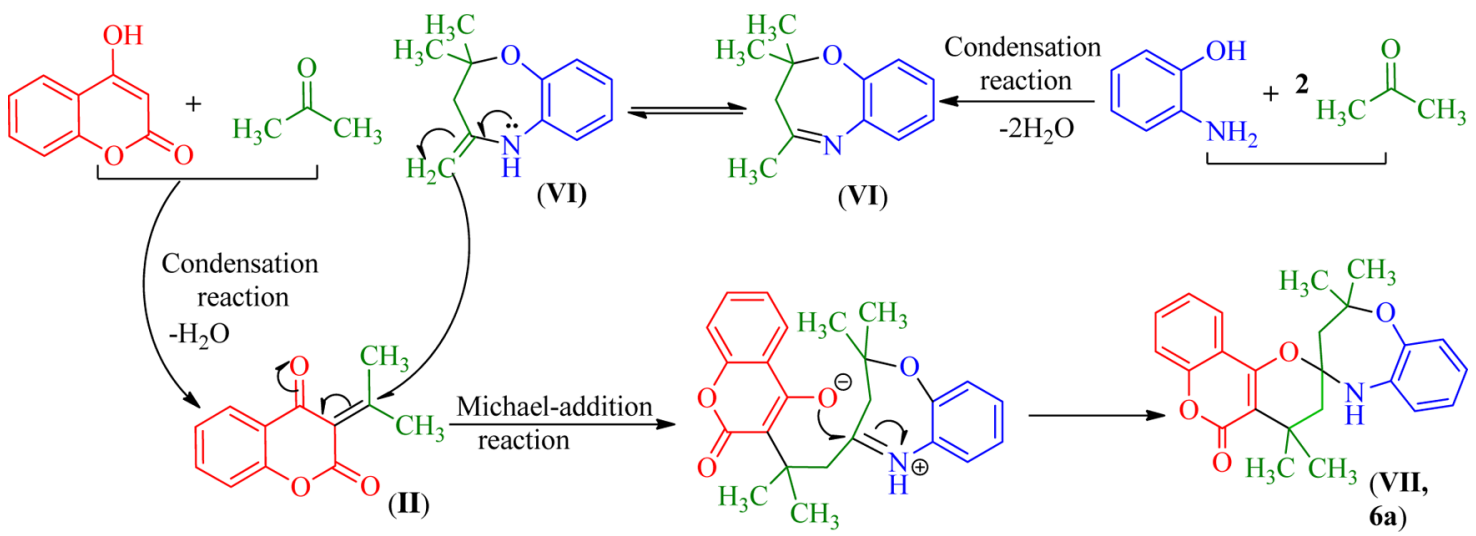

Scheme 5. Control Experiment of the Five-Molecule Cascade Reaction of 4-Hydroxychromen-2-one, 2-Aminophenol, and Acetone

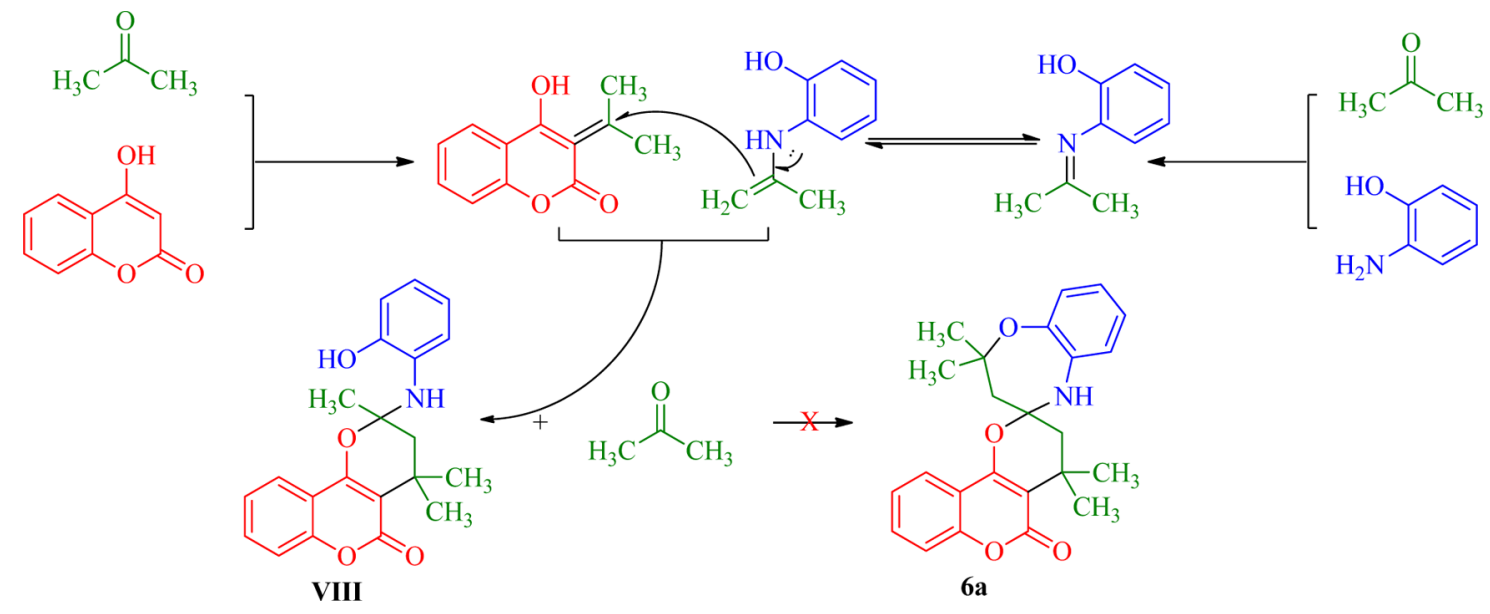

successfully identified by HRMS. On the basis of the findings, the possible reaction mechanism was proposed as following (Scheme 2): first, acetone reacts respectively with aniline and 4hydroxychromen-2-one to form two intermediates, isopropylidenephenylamine or iso-propenylphenylamine (I), and 3-iso-propylidenechroman-2,4-dione (II). Subsequently, the Michael-addition-type reaction of I and II provides the target compound 2,4,4-trimethyl-2-phenylamino-3,4-dihydro- $2 \mathrm{H}$ pyrano[3,2-c]chromen-5-one (III, 4a), in which the intermediate $\mathbf{I}$ acts as an electron-donating substrate.
Second Kind of Reaction: Five-Molecule Reaction. On the basis of the deduced mechanism of the four-molecule reaction, as shown above, and the reported information of 2,2-dimethyl4-methylene-2,3,4,5-tetrahydro- $1 H$-benzo $[b][1,4]$ diazepine (IV), ${ }^{19,20}$ the reaction mechanism for the formation of $4,4,4^{\prime}, 4^{\prime}$ tetramethyl-1,3,3',4,4',5-hexahydro-5' $H$-spiro [benzo $[b][1,4]$ diazepine-2,2'-pyrano[3,2-c]chromen]-5'-one (V) via a fivemolecule reaction is proposed in Scheme 3. To further confirm the plausible reaction pathway, the intermediate IV was prepared and designated as a substrate for this reaction. The treatment of IV and 4-hydroxychromen-2-one in acetone under 
Table 1. Condition Optimization of the Four-Molecule Cascade Reaction ${ }^{a}$

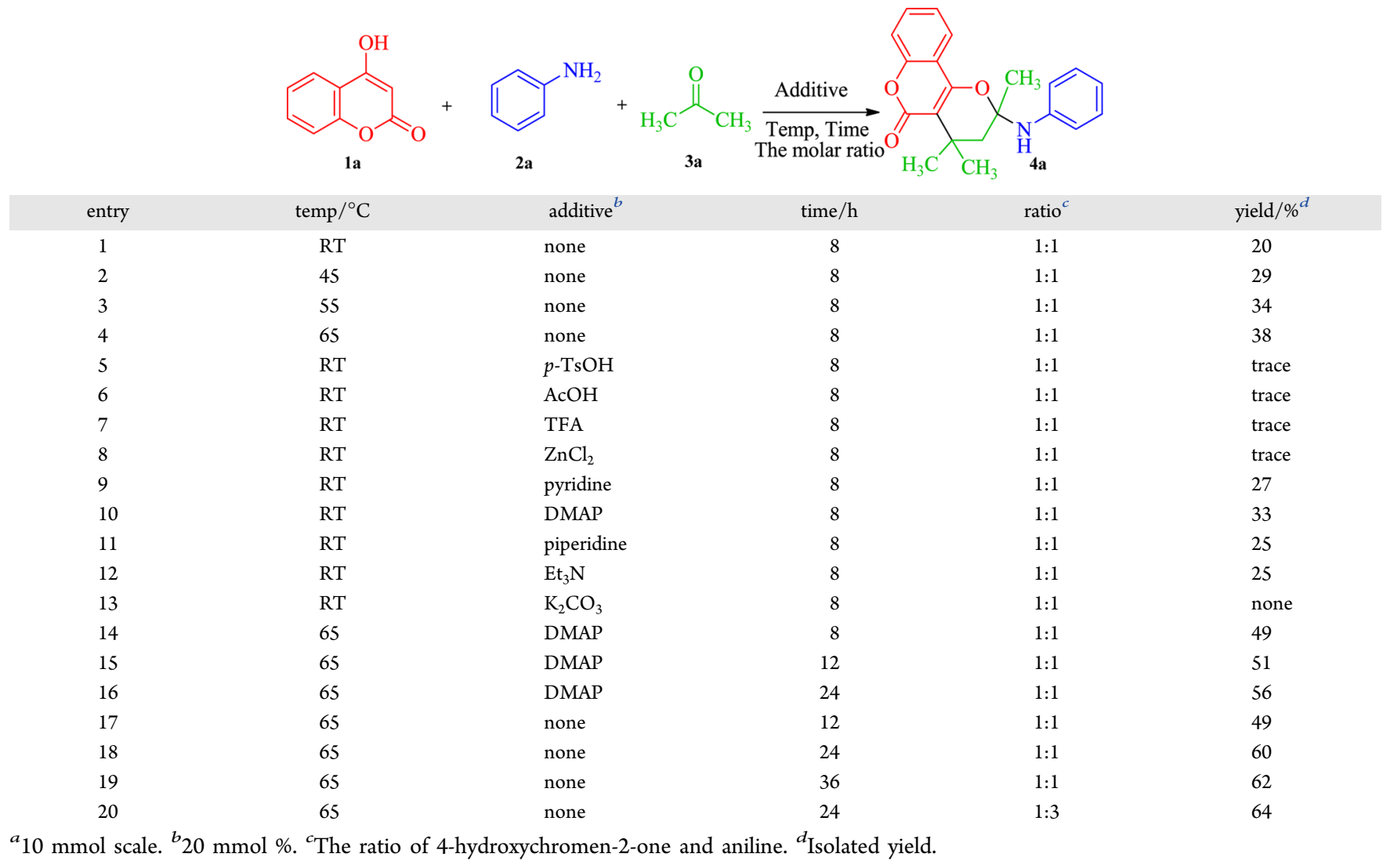

otherwise identical conditions gave the desired product $\mathbf{5 a}$ in good yield. On the basis of the result and in combination with the fact that II and IV were successfully identified by HRMS, we concluded that the five-molecule reaction should use II and IV as the active intermediates, which supported our proposed mechanism listed in Scheme 3.

Similarly, II and VI should be employed as the key intermediates for the formation of $2,2,4^{\prime}, 4^{\prime}$-tetramethyl$2,3,3^{\prime}, 4^{\prime}$-tetrahydro- $5 H, 5^{\prime} H$-spiro-[benzo[ $\left.b\right][1,4]$-oxazepine$4,2^{\prime}$-pyrano[3,2-c]chromen]-5'-one (VII, 6a), and thus, a plausible mechanism is proposed in Scheme 4.

Furthermore, 2-(2-hydroxyphenylamino)-2,4,4-trimethyl-3,4dihydro-2H,5H-pyrano-[3,2-c]-chromen-5-one (VIII) was prepared and designated as a proposed intermediate to verify this reaction mechanism. Thus, VIII was treated with acetone, and the obtained mixture was refluxed for $8 \mathrm{~h}$. However, compound 6a was not obtained (Scheme 5). The result revealed that this reaction should use VI, instead of VIII, as the reaction intermediate.

Reaction Conditions Optimization. Screening for the Reaction Temperature. Initially, aniline, 4-hydroxychromen-2one, and acetone were employed as the model substrates for the optimization of the reaction conditions. As shown in Table 1 , we found that temperature was crucial for the reaction. The reaction proceeded very slowly at room temperature, and the product yield could be improved with the increase of reaction temperature (entries 1-4). As the boiling point of acetone is 56 ${ }^{\circ} \mathrm{C}$ under air, here, the reaction temperature was selected to be $60{ }^{\circ} \mathrm{C}$.

Screening for the Reaction Time and Molecular Molar Ratio. Moreover, our investigation showed that the reaction time and molecular molar ratio of the three components played an important role in the reaction outcome. Through a set of investigations, we found that: (1) refluxing the reaction for $24 \mathrm{~h}$ offered the highest yield; (2) the optimal molecular molar ratio of 4-hydroxychromen-2-one/aniline/acetone was 1:1:10.

Screening for the Catalyst and Solvent. To further optimize the reaction conditions, several simple catalysts were also investigated. The results indicated that the application of basic catalysts (entries 9-12), such as triethylamine $\left(\mathrm{Et}_{3} \mathrm{~N}\right)$, could enhance the reaction rate when the reaction proceeded at room temperature, whereas the catalytic efficiency of triethylamine was not obvious when the reaction was carried out at refluxing temperature (entries 14-16). Pyridine, piperidine, and $N, N$-dimethylpyridine (DMAP) exhibited the same behavior as that of triethylamine. Furthermore, the presence of $\mathrm{K}_{2} \mathrm{CO}_{3}$ obviously inhibited the outcome of the reaction (entry 13). Inspired by these results, a slight excess of aniline was used instead of the additional basic catalysts in this work.

Acids, such as $p$-toluene sulfonic acid $(p-\mathrm{TsOH})$, acetic acid $(\mathrm{AcOH})$, trifluoroacetic acid (TFA), and zinc chloride $\left(\mathrm{ZnCl}_{2}\right)$, also obviously inhibited the process (entries 5-8), which further confirmed the reaction mechanism.

The solvent effect on the reaction was also investigated, and the results showed that the utilization of solvents, such as tetrahydrofuran, dichloromethane, butanone, toluene, or $[1,4]$ dioxane, did not obviously improve the product yield, and therefore, a slight excess of acetone was used in this work.

In summary, and with the aim to meet the objectives of green chemistry, the optimal conditions were identified as follows: the mole ratio of 4-hydroxychromen-2-one/aniline/acetone was 1.00:1.05:10.00, and the reacting mixture was refluxed at $60{ }^{\circ} \mathrm{C}$ for $24 \mathrm{~h}$. 
Scheme 6. Substrate Scope of Substituted Anilines and Four-Molecule Reaction Products ${ }^{a}$
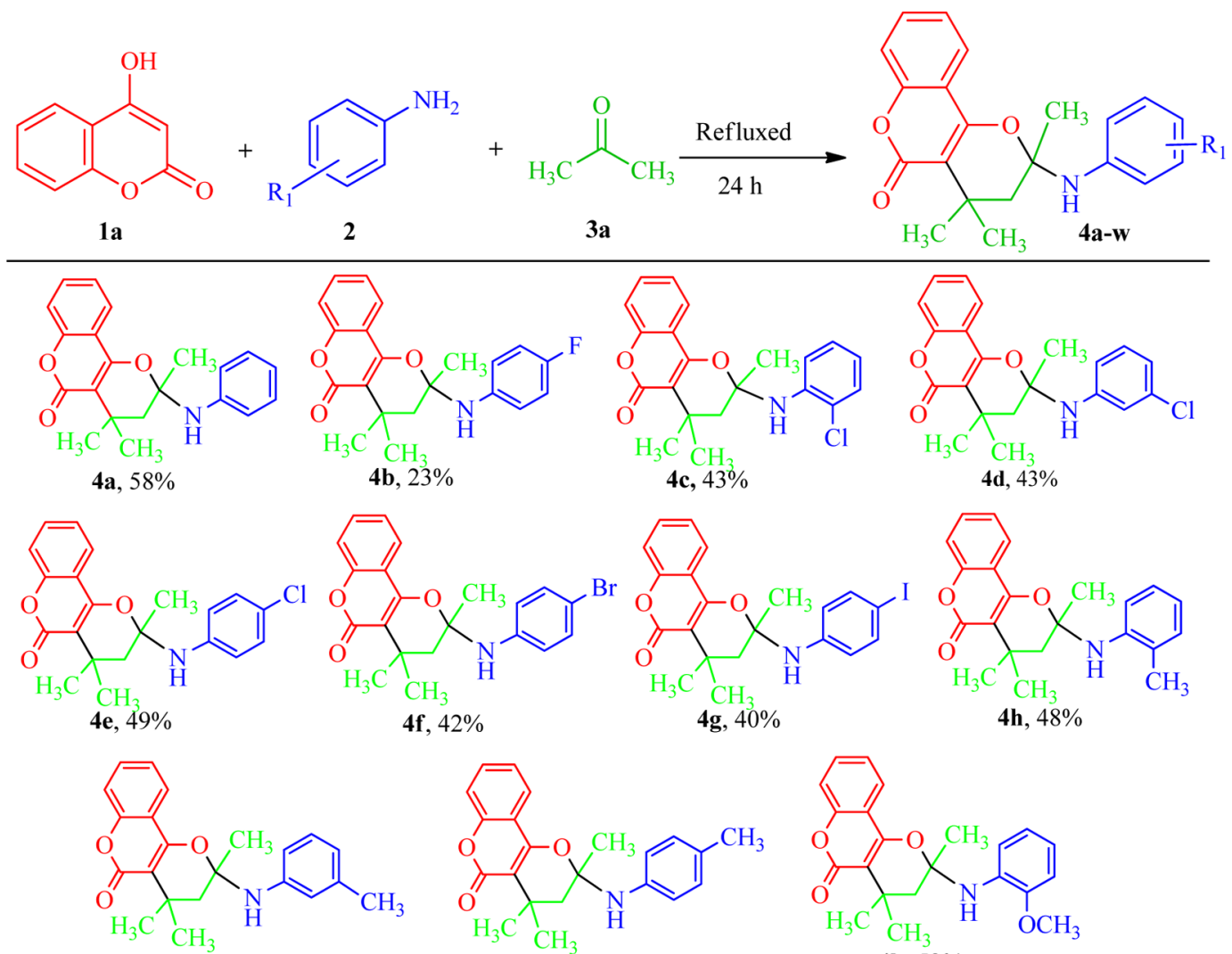

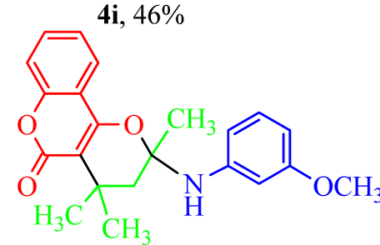

$41,52 \%$

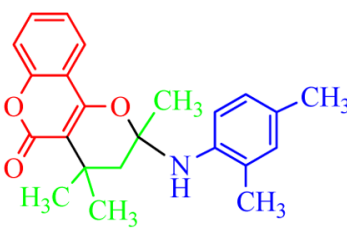

40, $61 \%$

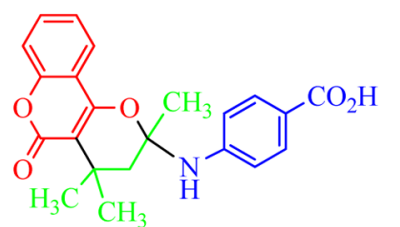

4r, NR

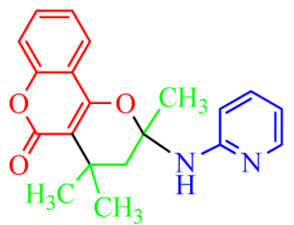

4u, NR $\mathbf{4 j}, 52 \%$

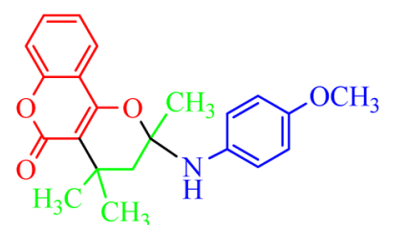

$4 \mathrm{~m}, 56 \%$

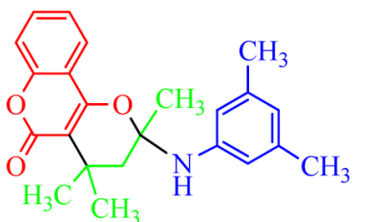

4p, $59 \%$

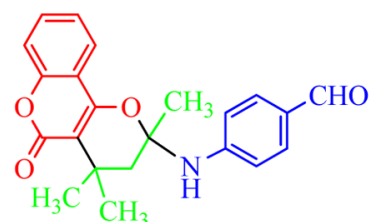

4s, NR

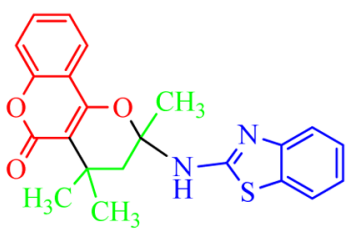

4v, NR
$4 \mathbf{k}, 52 \%$<smiles>CC(=O)c1ccc(NC2(C)CC(C)(C)c3c(c4ccccc4oc3=O)O2)cc1</smiles>

4n, $19 \%$

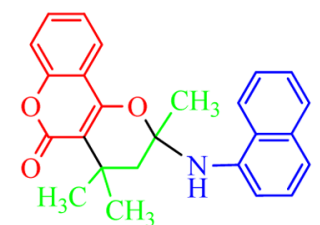

$$
\text { 4q, } 38 \%
$$

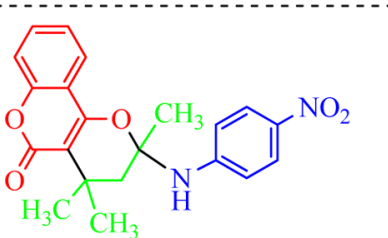

4t, NR

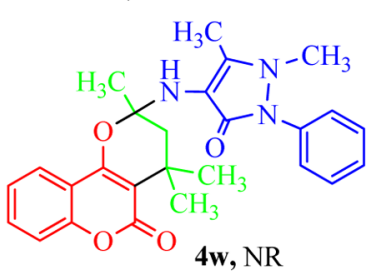

${ }^{a}$ Isolated yields. NR means no desired product was formed.

Substrate Scope of Substituted Anilines. Having the optimized conditions in hand, the scope of the reaction with respect to various anilines was then evaluated (Scheme 6). To our delight, we found that the developed catalyst- and solvent- 
Scheme 7. Five-Molecule Reaction for Substituted $o$-Phenylenediamines or o-Aminophenols and Their Products 5a-d and 6a$c^{a}$

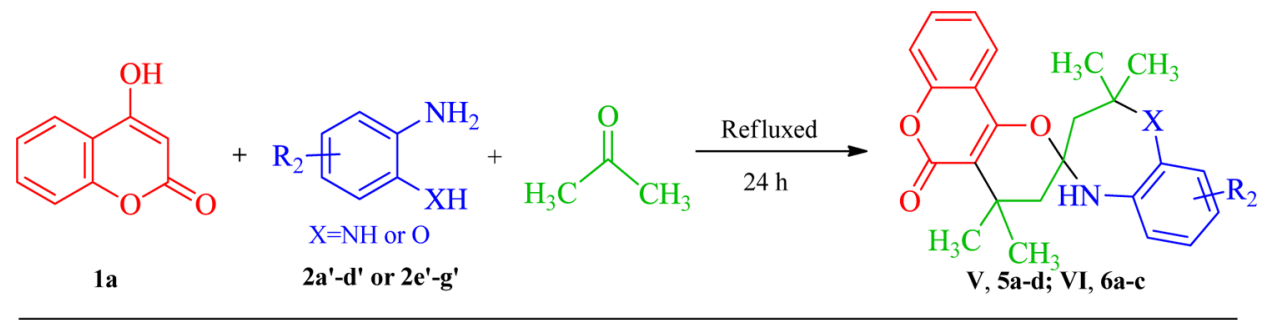<smiles>CC1CC2(CC(C)(C)c3c(c4ccccc4oc3=O)N2)Nc2ccccc2N1</smiles>

5a, $66 \%$<smiles>Cc1ccc2cc1NC1(CC(C)(C)N2)CC(C)(C)c2c(c3ccccc3oc2=O)O1</smiles>

5b, $41 \%$<smiles>CC1(C)CC2(CC(C)(C)c3c(c4ccccc4oc3=O)O2)Nc2cc(Cl)ccc2N1</smiles>

5c, $37 \%$<smiles>CC1(C)CC2(CC(C)(C)c3c(c4ccccc4oc3=O)O2)Nc2cc([N+](=O)[O-])ccc2N1</smiles>

5d, $20 \%$<smiles>CC1(C)CC2(CC(C)(C)c3c(c4ccccc4oc3=O)O2)Nc2ccccc2O1</smiles><smiles>Cc1ccc2c(c1)OC(C)(C)CC1(CC(C)(C)c3c(c4ccccc4oc3=O)O1)N2</smiles><smiles>Cc1ccc2c(c1)NC1(CC(C)(C)O2)CC(C)(C)c2c(c3ccccc3oc2=O)O1</smiles>

${ }^{a}$ Isolated yields.<smiles>O=C1CC(=O)c2ccccc21</smiles>

$1 H$-Indene1,3(2H)-dione<smiles>O=C1CCCC(=O)C1</smiles>

Cyclohexane-<smiles>Cc1cc(O)cc(=O)o1</smiles>

4-Hydroxy-6methyl-2-pyrone<smiles>CC(=O)CC(C)=O</smiles>

Pentane-

2,4-dione<smiles>CCOC(=O)CC(C)=O</smiles>

Ethyl 3-oxobutanoate

Figure 1. Structures of screened $\beta$-diketone compounds to replace 4-hydroxychromen-2-one.

free system proved to be broadly applicable, thus delivering the desired products $\mathbf{4 a}-\mathbf{q}$ in moderate to good yields, in which the electron-donating anilines gave relatively higher yields than the electron-withdrawing substrates, suggesting that the electrical properties of the substituent played a key role in this transformation. Further investigations showed that no reaction was detected when those bearing the strong electron-withdrawing group on the benzene ring, including the carboxyl, formyl, and nitro substituents, were employed as the aniline substrates. The results further confirmed our above conclusion and also hinted at the reaction mechanism because a larger electron density was more likely to occur during the first concentration reaction than the second Michael-addition reaction. That is to say, the electron density of the nitrogen atom of aniline played a vital role in determining the MCR outcome. To better define the scope of this reaction, we further explored several heterocyclic amines such as 2-aminopyridine $(\mathbf{2 u})$, benzothiazol-2-ylamine (2v), and 4-amino-1,5-dimethyl2-phenyl-1,2-dihydro-pyrazol-3-one (2w). However, no ex- pected products were observed, indicating that the presence of the phenyl group was crucial for this MCR.

Surprisingly, another kind of bran-new product, named 4,4,4' $4^{\prime} 4^{\prime}$-tetramethyl-1,3,3',4,4',5-hexahydro- $5^{\prime} H$-spiro[benzo$[b][1,4]$ diazepine-2,2' -pyrano-[3,2-c] chromen $]-5^{\prime}$-one, was formed easily by using $o$-phenylenediamine as the substrate. Encouraged by this finding, we sought to investigate the scope and limitations of $o$-phenylenediamine substrates. As given in Scheme 7 , we were pleased to find that the reaction proceeded smoothly to give the desired products $\mathbf{5 a}-\mathbf{d}$ in moderate to good isolated yields, and both electron-donating and -withdrawing groups at the para-position were all well tolerated. Of note, $o$-aminophenol was also found to suitable substrates for this reaction because the treatment of $o$-aminophenol and its analogues with 4-hydroxychromen-2-one and acetone gave their corresponding products $6 a-c$ in $39-49 \%$ isolated yields.

Substrate Scope of 4-Hydroxychromen-2-ones. To further probe the substrate tolerance of this reaction, we investigated the scope of $\beta$-diketone compounds, such as $1 \mathrm{H}$ indene-1,3(2H)-dione, 1,3-cyclohexanedione, 4-hydroxy-6- 
<smiles>O=CCc1ccccc1C=O</smiles>

Benzaldehyde

\section{$\mathrm{CH}_{3} \mathrm{CH}_{2} \mathrm{CHO}$}

Propionaldehyde

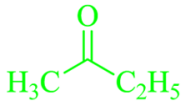

Butan-2-one<smiles>CC(=O)CC(C)=O</smiles>

Pentane-2,4-dione<smiles>CC(=O)CCC(C)=O</smiles>

Hexane-2,5-dione<smiles>O=C1CCC2CCCC12</smiles>

Cyclopentanone

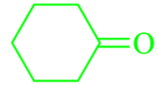

Cyclohexanone

Figure 2. Structures of screened aldehyde and ketone compounds to replace acetone.

Scheme 8. Investigation of Aromatic Aldehyde Compounds (Benzaldehyde) for this Reaction

(a)<smiles>O=c1cc(O)c2ccccc2o1</smiles><smiles>O=Cc1ccccc1</smiles><smiles>Nc1ccccc1</smiles><smiles>CC</smiles><smiles>C=Nc1ccccc1</smiles><smiles>O=C1Oc2ccccc2C(=O)/C1=C/c1ccccc1</smiles>

(b)<smiles>CC(C)CC1CCCCC1</smiles><smiles>O=c1oc2ccccc2c(O)c1C(c1ccccc1)c1c(O)c2ccccc2oc1=O</smiles>

methyl-2-pyrone, pentane-2,4-dione, and ethyl 3-oxo-butanoate (for their detailed chemical structures, see Figure 1) to replace 4-hydroxychromen-2-one. However, no reaction was observed in the two catalyst- and solvent-free MCR systems.

Substrate Scope of Ketone Compounds. Moreover, some carbonyl compounds, such as aromatic aldehydes, aliphatic-aldehydes, butanone, 2-pentone, pentane-2,4-dione, hexane-2,5-dione, cyclohexanone, and cyclopentanone (for their detailed chemical structures, see Figure 2), were also scanned to replace acetone for the two MCRs. However, the results also showed that no desired products were obtained.

It should be noted that aromatic aldehyde compounds, such as benzaldehyde, could react smoothly with 4-hydroxychromen2-one and aniline to provide 3-benzylidenechromane-2,4-dione and N,1-diphenylmethanimine as the final products (Scheme 8 ). However, $N, 1$-diphenylmethanimine could not further react with 3-benzylidenechromane-2,4-dione via Michael-addition reaction (Scheme 8a). This might be because N,1-diphenylmethanimine could not be converted to the enamine form via a 1,3-proton shift. Therefore, it did not possess the capability in the reaction with 3-benzylidenechromane-2,4-dione to achieve Michael addition. Alternatively, the result from HRMS analysis showed that benzaldehyde reacted with 2 -fold of 4-hydroxychromen-2-one to form 3,3'-(phenylmethylene)bis-(4-hydroxy-2H-chromen-2-one) (Scheme $8 \mathrm{~b})$.

\section{CONCLUSIONS}

In summary, we have established two simple and practicable reactions for one-pot constructing three kinds of compounds with a novel molecular skeleton, including 2,4,4-trimethyl-2(phenylamino)-3,4-dihydro-2H,5H-pyrano[3,2-c] chromen-5- ones, 4,4,4' $4^{\prime} 4^{\prime}$-tetramethyl-1,3,3' ${ }^{\prime}, 4,4^{\prime}, 5$-hexahydro-5' $H$-spiro[benzo $[b][1,4]$ diazepine-2,2' -pyrano[3,2-c] chromen]-5'-ones, and $2,2,4^{\prime}, 4^{\prime}$-tetramethyl-2,3,3', $4^{\prime}$-tetrahydro- $5 H, 5^{\prime} H$-spiro[benzo[b][1,4] oxazepine-4,2'-pyrano[3,2-c]chromen $]-5^{\prime}$-ones, when commercially and easily available 4-hydroxychromen-2one, acetone, and substituted anilines were employed as the versatile substrates. The bran-new four-molecule and fivemolecule cascade reactions could be carried out smoothly under mild and catalyst- and solvent-free conditions with broad substrate/functional group tolerance and excellent siteselectivity. Thus, they should have the potential for broad synthetic utility in organic synthetic chemistry, i.e., for one-pot and green syntheses of bioactive compounds, natural products, and organic building blocks that contain the three key basic frameworks.

\section{EXPERIMENTAL SECTION}

General Experimental Section. The starting materials were commercially available and were used without further purification. The products were isolated by column chromatography on silica gel. Melting points were determined by a WRS1B (Shanghai Precise Science Instrument Co. Ltd.). ${ }^{1} \mathrm{H}$ NMR and ${ }^{13} \mathrm{C}$ NMR spectra were recorded on Bruker $400 \mathrm{MHz}$ and Bruker $300 \mathrm{MHz}$ spectrometers respectively, using $\mathrm{CDCl}_{3}$ as solvent. Element analysis was performed on an elemental analyzer (Germany Elementar Co. Ltd.). HRMS was performed on an Agilent QTOF-MS 6540. Single crystal data were collected on a Smart 1000 CCD single crystal diffractometer.

General Procedure for the Synthesis of $4 a-q$. A mixture of $1.62 \mathrm{~g}$ (10 mmol) of 4-hydroxychromen-2-one, 10.5 $\mathrm{mmol}$ of the corresponding anilines, and $5.80 \mathrm{~g}$ (100 mmol, 7.4 
Table 2. Information of the Corresponding Single Crystals

Entry

$\mathrm{mL}$ ) of acetone was stirred for $24 \mathrm{~h}$ under refluxing; then, it was concentrated under vacuum to obtain a residue that was separated by column chromatography with ethyl acetate and petroleum ether as the eluents to afford the corresponding products. All other compounds were synthesized in a similar manner, with the yields listed in the main text calculated from the isolated, pure products.

General Procedure for the Synthesis of $4 a$ on 10Gram Scale. A mixture of $16.2 \mathrm{~g}(100 \mathrm{mmol})$ of 4hydroxychromen-2-one, $9.77 \mathrm{~g}(105 \mathrm{mmol})$ of aniline, and $58.0 \mathrm{~g}(1000 \mathrm{mmol}, 74 \mathrm{~mL})$ of acetone was stirred for $24 \mathrm{~h}$ under refluxing. The reaction mixture was cooled to room temperature, and the product precipitated. The precipitated product was filtered and washed with petroleum ether to get $18.0 \mathrm{~g}$ of pure product (yield: $54 \%$ ).

General Procedure for the Synthesis of $5 a-d$ and $6 a-$ c. A mixture of $1.62 \mathrm{~g}(10.0 \mathrm{mmol})$ of 4-hydroxychromen-2one, $10.5 \mathrm{mmol}$ of the corresponding $o$-phenylenediamine or $o$ aminophenol, and $5.80 \mathrm{~g}(100 \mathrm{mmol}, 7.4 \mathrm{~mL})$ of acetone was stirred for $24 \mathrm{~h}$ under refluxing; then, it was concentrated under vacuum to obtain a residue that was separated by column chromatography with ethyl acetate and petroleum ether as the eluents to give the corresponding products. All other compounds were synthesized in a similar manner, with the yields listed in the main text calculated from the isolated, pure products.

Single Crystal Preparation and the Relevant Information. Compound $4 \mathrm{a}(100 \mathrm{mg}(0.3 \mathrm{mmol}))$ was dissolved in 2 $\mathrm{mL}$ of dichloromethane and the mixture was left standing for more than $48 \mathrm{~h}$. The obtained crystal was collected and analyzed. Single crystals of 5a and 6a were obtained based on the same method. The single crystal structures were analyzed and the obtained data were deposited in the Cambridge Crystallographic Data Centre database. The detailed information of the three crystals is listed in Table 2.

\section{ASSOCIATED CONTENT}

Supporting Information

The Supporting Information is available free of charge on the ACS Publications website at DOI: 10.1021/acsomega.7b02017.

Detailed experimental procedure and characterization of all new products $\left({ }^{1} \mathrm{H}\right.$ and ${ }^{13} \mathrm{C}$ NMR spectra) (PDF)

\section{AUTHOR INFORMATION}

\section{Corresponding Authors}

*E-mail: yiwei@gzhmu.edu.cn. Tel: +86-20-37104196. Fax: +86-20-37104196 (W.Y.).

*E-mail: songhc2007@163.com. Tel: +86-20-84110918. Fax: +86-20-84112245 (H.S.).

ORCID $\odot$

Guoxun Zhu: 0000-0003-4410-789X

Wei Yi: 0000-0001-7936-9326

Notes

The authors declare no competing financial interest.

\section{ACKNOWLEDGMENTS}

We thank the Special Capacity Construction of Guangdong Academy of Sciences (2017GDASCX-0104) and Guangdong Science and Technology Planed Project (2017A070702017) for financial support for this study.

\section{REFERENCES}

(1) Nandaluru, P. R.; Bodwell, G. J. Org. Lett. 2012, 14, 310-313.

(2) Soumya, T. V.; Muhammed Ajmal, C.; Bahulayan, D. Bioorg. Med. Chem. Lett. 2017, 27, 450-455.

(3) (a) Volla, C. M.; Atodiresei, I.; Rueping, M. Chem. Rev. 2014, 114, 2390. (b) Levi, L.; Müller, T. J. Chem. Soc. Rev. 2016, 45, 2825. (c) Rotstein, B. H.; Zaretsky, S.; Rai, V.; Yudin, A. K. Chem. Rev. 2014, 114, 8323. (d) Cho, H. Y.; Morken, J. P. Chem. Soc. Rev. 2014, 43, 4368. (e) Estévez, V.; Villacampa, M.; Menéndez, J. C. Chem. Soc. Rev. 2014, 43, 4633. (f) Brauch, S.; van Berkel, S. S.; Westermann, B. Chem. Soc. Rev. 2013, 42, 4948. (g) Marson, C. M. Chem. Soc. Rev. 2012, 41, 7712. (h) Dömling, A.; Wang, W.; Wang, K. Chem. Rev. 2012, 112, 3083. (i) Ruijter, E.; Scheffelaar, R.; Orru, R. V. Angew. Chem., Int. Ed. 
2011, 50, 6234. (j) Jiang, B.; Rajale, T.; Wever, W.; Tu, S. J.; Li, G.

Chem. - Asian J. 2010, 5, 2318.

(4) Anastas, P. T.; Warner, J. C. Green Chemistry: Theory and Practice; Oxford University Press, 2000; pp 19758-19771.

(5) Jiang, H.; Tian, Y.; Tian, L.; Li, J. RSC Adv. 2017, 7, 3230032303 .

(6) Zhu, Q.; Yuan, Q.; Chen, M.; Guo, M.; Huang, H. Angew. Chem., Int. Ed. 2017, 56, 5101-5105.

(7) Nguyen, M. H.; Imanishi, M.; Kurogi, T.; Smith, A. B., 3rd J. Am. Chem. Soc. 2016, 138, 3675-3678.

(8) Multicomponent Reactions in Organic Synthesis; Zhu, J., Wang, Q., Wang, M. X., Eds.; John Wiley \& Sons: 2014.

(9) Jia, S.; Su, S.; Li, C.; Jia, X.; Li, J. Org. Lett. 2014, 16, 5604-5607.

(10) D'yakonov, V. A.; Kadikova, G. N.; Gazizullina, G. F.; Khalilov, L. M.; Dzhemilev, U. M. Tetrahedron Lett. 2015, 56, 2005-2007.

(11) Cheng, B.; Sunderhaus, J. D.; Martin, S. F. Tetrahedron 2015, $71,7323-7331$.

(12) Gilley, C. B.; Buller, M. J.; Kobayashi, Y. Org. Lett 2007, 9, $3631-3634$

(13) Evjen, S.; Fiksdahl, A. Synth. Commun. 2017, 47, 1392-1399.

(14) Govindhan, M.; Subramanian, K.; Chennakesava Rao, K.; Easwaramoorthi, K.; Senthilkumar, P.; Perumal, P. T. Med. Chem. Res. 2015, 24, 4181-4190.

(15) Lin, P. Y.; Yeh, K. S.; Su, C. L.; Sheu, S. Y.; Chen, T.; Ou, K. L.; Lin, M. H.; Lee, L. W. Molecules 2012, 17, 10846-10863.

(16) Latif, N. A. A.; Batran, R. Z.; Khedr, M. A.; Abdalla, M. M. Bioorg. Chem. 2016, 67, 116-129.

(17) Li, Z. P.; Li, J.; Qu, D.; Hou, Z.; Yang, X. H.; Zhang, Z. D.; Wang, Y. K.; Luo, X. X.; Li, M. K. J. Pharm. Pharmacol. 2015, 67, 573582.

(18) Huang, J.; Zhou, J.; Song, S.; Song, H.; Chen, Z.; Yi, W. Tetrahedron 2015, 71, 8628-8636.

(19) Patil, V. D.; Sutar, N. R.; Gidh, P. V.; Patil, K. P. Heterocycl. Lett. 2016, 6, 61 .

(20) Jamatia, R.; Gupta, A.; Dam, B.; Saha, M.; Pal, A. K. Green Chem. 2017, 19, 1576-1585. 